\title{
Successful Use of Graded Exposure Therapy in the Treatment of Social Phobia in a 10 year old Child
}

\author{
Dr. Satyakam Mohapatra \\ Mental Health Institute, Department of Psychiatry, SCB Medical College, Cuttack
}

\section{ABSTRACT}

Social phobia is one of the most common psychological disorders seen in children and adolescents. The paucity of literature and lack of training in the behavioural treatment of children with social phobia among health care professionals has made their treatment difficult. The purpose of the present case report was to demonstrate the utility of behavioral treatment (graded exposure therapy) for social phobia in children.

\section{INTRODUCTION}

Social phobia is one of the most common psychological disorders seen in children and adolescents. Studies from India show that the prevalence of social phobia in children and adolescents varies between $0.19 \%-0.27 \%{ }^{[1,2]} .60 \%$ children with social phobias have co morbid internalizing or externalizing disorders ${ }^{[3]}$. Because of the high comorbidity rates, social phobia places youth at risk for long term problems across domains of education, social relationships, and employment. Unfortunately, paucity of literature exists regarding the treatment of social phobia in young children, despite the knowledgethat traditional techniques (i.e., cognitivebehavioral therapy [CBT]) may not be practical. The purpose of this article is to present a case of 10-yearold child where graded exposure therapy was done successfully for treatment of social phobia.

\section{CASE HISTORY}

Master A, 10-year-old child with uneventful birth and developmental history without past and family history of psychiatric illness presented with complaints of difficulty in reading in class in front of all classmates and teachers, difficulty in answering questions in classroom, difficulty interacting with classmates from last 4 years. He also avoided interacting with known and unknown people who came to his home. He had difficulty in answering questions in viva examination and difficulty in performing on stage in school functions. On assessment his IQ was $115^{[4]}$. According to DSM -IV TR a diagnosis of social phobia was made. On Social Anxiety Scale for children-revised $\left(\right.$ SASC-R) ${ }^{[5]}$ the child scored 58. It was planned to treat the child with only non-pharmacological method. The patient was assessed for suitability of cognitive behavioural therapy but he was not able to understand the cognitive concept of CBT. So graded exposure therapy in vivo was started. Hierarchy of phobic cues was made after discussion with child and mother. The first task selected for exposure was the least feared phobic cue in the hierarchy list i.e. reading infront of others. So he was asked to recite a poem from his own book in front of all residents of our department. The child was not able to maintain eye to eye contact with the residents while reciting the poem, he was reciting in a hurry, 
Successful use of graded exposure therapy in the treatment of social phobia in a 10 year old child

looking anxious, and reciting poems without any emotions and feelings. He continued his recitation for 5 minutes in this manner. After 5 minutes he recited in a better way. He was more confident, reciting in a slow speed than before, not looking as anxious as earlier. He continued this for next 10 minutes. He was appreciated and encouraged by all residents present there including his mother. $\mathrm{He}$ was given homework to recite poems in front of his class and his mother was told to collect information about his performance from the teacher. In next visit homework assessment showed slight improvement in his performance. The patient was moved up in the hierarchy of phobic cues as soon as anxiety caused by easier ones decreased. The earlier one was repeated later on and incorporated into everyday life through homework assignment. Reinforcement was given to the child constantly in the form of praise and small prizes following completion of the task. Every week two sessions were done. After 8 sessions of therapy Social Anxiety Scale for children-revised (SASC-R) showed a score of 40 . There was improvement in interaction with friends and teachers, performance in viva examination improved, the child was able to answer questions in the class. It was planned to do 2-3 more sessions by moving up in the hierarchy of phobic cues and to continue homework assignment with continuous reinforcement to the child.

\section{DISCUSSION}

Fears in children are highly concrete ${ }^{[6]}$, and therefore, the cognitive aspects of CBT (e.g., altering schemas, cognitive distortions) are beyond the developmental capabilities of children. Efficacy of behavioral techniques in treating phobias in children has been well established ${ }^{[7,8]}$. The purpose of the present case report was to demonstrate the utility of behavioral treatments for social phobia in children. Our case has shown significant improvement with 8 sessions of graded exposure therapy. Exact rules of graded exposure therapy are usually difficult to follow in children with phobia. That also happened in our case. The steps for completion of the fear hierarchy and session structure were not completely standardized. So it is important to individualize the therapy as per the child's need to get the best result. The paucity of literature and lack of training in the behavioural treatment of children with social phobia among health care professionals has made their treatment difficult. More research in the field of behavioural treatment for different psychiatric disorders in children and adolescents is required.

\section{REFERENCE}

1. Indian Council of Medical Research. Epidemiological study of child and adolescent psychiatric disorders in urban and rural areas. ICMR Bulletin.2001. 31, 54-55.

2. Mohapatra S, Agarwal V, Sitholey P, Arya A. A clinical study of anxiety disorders in children and adolescents from North Indian children and adolescents clinic. Asian Journal of Psychiatry. 2014. (8) 84-88

3. Beidel, D.C., Turner, S.M., Morris, T.L., et al.,. Psychopathology of childhood social phobia. Journal of the American Academy of Child and Adolescentn Psychiatry. 1999. 38 (6) 643-650.

4. Raven, J., Raven, J.C., Court, J.H. Manual for Raven's Progressive Matrices and Vocabulary Scales. Harcourt Assessment, San Antonio, TX.2003

5. AML \& Wendy L. Stone WL. Social Anxiety Scale for Children-Revised : Factor Structure and Concurrent Validity. Journal of Clinical Child Psychology. Volume 22, Issue 1, 1993

6. Gullone, E. The development of normal fear: A century of research. Clinical Psychology Review, 2000. 20, 429-45

7. Davis, T. E., III., May, A. C., \& Whiting, S. E. Evidencebased treatment of anxiety and phobia in children and adolescents: Current status and effects on the emotional response. Clinical Psychology Review, 2011. 31, 592-602.

8. Hirshfeld-Becker, D. R., Mosek, B., Henin, A., Blakely, L. R., Rettew, D. C., Dufton, L., Biederman, J. Cognitive-behavioral intervention with young anxious children. Harvard Review of Psychiatry. 2008, 16, 113-125. 